\title{
Myocardial Glucose Clearance by Aspalathin Treatment in Young, Mature, and Obese Insulin-Resistant Rats
}

Authors

Sybrand Engelbrecht Smit ${ }^{1}$, Rabia Johnson ${ }^{1,2}$, Mignon Alberta Van Vuuren ${ }^{1}$, Barbara Huisamen ${ }^{1,2}$

Affiliations

1 Division of Medical Physiology, Stellenbosch University, Cape Town, South Africa

2 Biomedical Research and Innovation Platform, South African Medical Research Council, Cape Town, South Africa

Key words

aspalathin, rooibos, obesity, insulin resistance,

hyperglycemia, cardiomyocytes

received February 10, 2017

revised July 10, 2017

accepted July 17, 2017

Bibliography

DOI https://doi.org/10.1055/s-0043-117415

Published online August 3, 2017 | Planta Med 2018; 84: 75-

82 @ Georg Thieme Verlag KG Stuttgart · New York I

ISSN 0032-0943

Correspondence

Mr. Sybrand E. Smit

Division of Medical Physiology, Faculty of Medicine and Health

Sciences, Stellenbosch University

Francie van Zijl Drive, Tygerberg, Cape Town 7505,

South Africa

Phone: + 27219389688 , Fax: + 27219389476

sybrande.smit@gmail.com

Supporting information available online at

http://www.thieme-connect.de/products

\section{ABSTRACT}

Rooibos, an indigenous South African plant ingested as herbal tea, is well known for its antioxidant effects. This in vitro study investigated aspalathin $\left(\mathrm{C}_{21} \mathrm{H}_{24} \mathrm{O}_{11}\right)$, a dihydrochalcone unique to rooibos, for hypoglycemic effects in the context of age- and obesity-induced insulin resistance and the mechanisms involved. Male Wistar rats were allocated into three groups: 16-30 weeks feeding with either standard rat chow or a high-caloric diet, or 6-10 weeks feeding with standard rat chow. Ventricular cardiomyocytes were isolated by collagenase perfusion digestion, and glucose uptake was determined by $2-\left[{ }^{3} \mathrm{H}\right]$-deoxyglucose accumulation. Viability was tested by trypan blue exclusion or propidium iodide staining. The high-caloric diet significantly increased body weight gain (508.5 \pm 50.0 vs. $417.3 \pm 40.0 \mathrm{~g})$, visceral adiposity (42.30 \pm 10.1 vs. $21.75 \pm 7.0 \mathrm{~g})$, and fasting blood glucose $(5.7 \pm 0.4$ vs. $4.7 \pm 0.1 \mathrm{mM})$. Aspalathin $(10 \mu \mathrm{M}$ for $90 \mathrm{~min})$ induced 2 $\left[{ }^{3} \mathrm{H}\right]$-deoxyglucose uptake in young cardiomyocytes $(37.2 \pm$ 13.9 vs. $25.7 \pm 2.5 \mathrm{pmol} 2-\left[{ }^{3} \mathrm{H}\right]$-deoxyglucose/mg protein) and enhanced insulin-mediated $2-\left[{ }^{3} \mathrm{H}\right]$-deoxyglucose uptake in control cells $\left(32.4 \pm 6.4\right.$ vs. $23.5 \pm 10.0$ pmol 2-[ $\left.{ }^{3} \mathrm{H}\right]$-deoxyglucose/mg protein), but failed to induce $2-\left[{ }^{3} \mathrm{H}\right]$-deoxyglucose uptake in high-caloric diet cells. Aspalathin induced glucose uptake in insulin-sensitive cardiomyocytes from young and aged rats, but not in high-caloric diet animals and enhanced the actions of insulin through a PI3K-dependent mechanism, resulting in an additive response.

\section{Introduction}

Cardiovascular diseases, the leading cause of death worldwide, constitute $31 \%$ of all annual global deaths (17.5 million people) [1]. This figure is aggravated by the presence of risk factors such as hyperglycemia, obesity, and insulin resistance, culminating in type 2 diabetes mellitus [2]. Since various current medications available to treat type 2 diabetes lose effectiveness after prolonged treatment [3] or become toxic to the pancreas, liver, and heart over time $[4,5]$, a search for alternatives has been instigated in recent years.

One promise of a safe natural alternative is rooibos [Aspalathus linearis L. (Burm.f.) R. Dahlgren (Leguminosae)], an indigenous herbal tea of South Africa. Rooibos exhibits antioxidant potential, antimutagenicity, and improves cardiovascular health in humans $[6,7]$. Furthermore, it was demonstrated that rooibos resensitized insulin signaling in $\mathrm{C} 2 \mathrm{C} 12$ skeletal muscle cells via specific biochemical pathways, including protein kinase B, also called Akt, and through activation of the insulin-independent adenosine monophosphate protein kinase pathway, which culminated in increased levels of glucose uptake via the GLUT4 [8]. The main phenolic compound within rooibos, aspalathin, has recently attracted interest for its potential in regulating glucose metabolism [8-11]. Aspalathin has been shown to induce glucose uptake directly in rat L6 skeletal muscle cells $[9,11]$. Treatment with aspalathin-enriched fractions also increased glucose uptake in mouse $\mathrm{C} 2 \mathrm{C} 12$ 


$\begin{array}{ll}\text { ABBREVIATIONS } \\ \text { 2DG } & \text { 2-[ }\left[{ }^{3} \mathrm{H}\right] \text {-deoxyglucose } \\ \text { Asp } & \text { aspalathin } \\ \text { FACS } & \text { fluorescence-activated cell sorting } \\ \text { FFA } & \text { free fatty acids } \\ \text { GLUT4 } & \text { glucose transporter } 4 \\ \text { HFD } & \text { high-fat, high-sucrose diet } \\ \text { HOMA-IR } & \text { homeostasis model assessment for insulin } \\ & \text { resistance } \\ \text { Ins } & \text { insulin } \\ \text { PI3K } & \text { phosphatidylinositol } 3 \text { kinase } \\ & \end{array}$

skeletal muscle cells [10]. Furthermore, treating palmitate-induced insulin-resistant $\mathrm{C} 2 \mathrm{C} 12$ skeletal muscle cells with either fermented or unfermented rooibos extract induced elevated glucose uptake levels [8]. In addition, dietary aspalathin suppressed elevated fasting blood glucose and improved impaired glucose tolerance in $o b / o b$ [11] and $d b / d b$ mice [9].

In view of previous observations and to deepen the understanding of myocardial glucose metabolism in ageing, obesity, and insulin resistance, aspalathin's glucose uptake potential in isolated cardiomyocytes from young (8 weeks), age-matched controls ( 22 weeks), and HFD ( 22 weeks: 6 weeks weaning +16 weeks of an HFD) rats were investigated.

\section{Results and Discussion}

The prevalence of obesity and insulin resistance increases the risk for cardiovascular diseases [1]. To investigate these conditions, a diet-induced obese and insulin-resistant Wistar rat model (HFD) (Table 1S, Supporting Information) was used. In the present study, the HFD rats had a significantly higher body weight gain ( $\vee$ Fig. 1A) and visceral fat content (Table 2S, Supporting Information) compared to age-matched controls (C), corroborating previous findings [12]. At 7-14 weeks old, the body weight of the young rats averaged $246.8 \pm 35.0 \mathrm{~g}(\mathrm{n}=38)$, whereas at 2432 weeks old, the control rats averaged $417.3 \pm 40.0 \mathrm{~g}(\mathrm{n}=22)$ and HFD rats $508.5 \pm 50.0 \mathrm{~g}(\mathrm{n}=20)$, averaging a body weight gain of $91.2 \mathrm{~g}$ or $22 \%(\mathrm{p}<0.001)$ in HFD rats ( $\boldsymbol{F}$ Fig. $1 \mathrm{~A})$. After 24-32 weeks of feeding, the visceral fat of the control rats averaged $21.8 \pm 7.0 \mathrm{~g}$ and HFD rats $42.3 \pm 10.0 \mathrm{~g}$, equating an average of $95 \%$ higher visceral fat $(p<0.001)$ (Table 2 S, Supporting Information). In genetically and environmentally susceptible individuals, chronic overnutrition and low energy expenditure cause the subcutaneous fat to saturate, consequently leading to enlarged adipocytes and visceral fat formation [13]. Furthermore, diet-induced visceral fat accumulation is an important precursor for insulin resistance [14].

One of the first clinical consequences of insulin resistance is a dysregulation in glucose homeostasis, the maintenance of blood glucose concentration within very narrow physiological limits [15]. This abnormality can be determined by measuring fasting blood glucose concentrations, which are closely regulated by endogenous glucose production and glucose utilization by insulin- sensitive tissues. In the present study, following overnight fasting, HFD rats had elevated basal blood glucose levels compared to the controls ( $5.7 \pm 0.4$ vs. $4.7 \pm 0.1 \mathrm{mM} ; \mathrm{p}<0.001)$ ( $>$ Fig. $1 \mathrm{~B}$ ). After an oral sucrose injection containing a disaccharide bond of glucose and fructose, the blood glucose levels of HFD rats continued to remain significantly elevated for up to $45 \mathrm{~min}(7.2 \pm 0.8$ vs. $5.4 \pm 1.1 \mathrm{mM} ; \mathrm{p}<0.05$ ), and only approached fasting blood glucose levels after 90 min compared to the 45 min for the control rats. In addition, the non-fasting blood glucose levels were also highest in the HFD rats $(7.8 \pm 1.0 \mathrm{mM})$, followed by similar levels for the control rats $(7.1 \pm 0.7 \mathrm{mM})$ and young rats $(7.3 \pm 0.8 \mathrm{mM})$ (Table 2S, Supporting Information). Further indication of insulin resistance in HFD rats includes raised fasting insulin levels (HFD: $14.58 \pm 2.0$ vs. control: $6.68 \pm 2.2 \mu \mathrm{lU} / \mathrm{mL}$; $\mathrm{p}<0.05$ ), constituting an increase in serum insulin levels of $118 \%$ and a higher HOMA-IR index (Table 2S, Supporting Information). In the present study, increasing concentrations of insulin elicited a weak response in glucose uptake in cardiomyocytes isolated from HFD rats ( $\bullet$ Fig. 1 C), corroborating previous studies using a similar model $[12,16]$. When comparing their respective glucose uptake responses, the young animals had the most robust response to increasing concentrations of insulin, with $10 \mathrm{nM}$ insulin having a significant $54 \pm 26 \%(n=6 ; p<0.001)$ increase and $100 n M$ insulin having a $97 \pm 35 \%(n=3 ; p<0.001)$ increase ( $\vee$ Fig. 1 C). The older control animals had a significant increase of $46 \pm 15 \%(n=5 ; p<0.01)$ and $56 \pm 19 \%(n=5 ; p<0.001)$, respectively, while the HFD group showed a saturation in glucose uptake with $10 \mathrm{nM}$ insulin increasing $37 \pm 21 \%(n=8 ; p<0.01)$ and a similar $36 \pm 22 \%(n=7$; $p<0.001)$ with $100 \mathrm{nM}$ compared to the basal uptake $(n=9)$ expected of insulin-resistant cardiomyocytes.

We propose that the mechanism for insulin resistance formation following an HFD is due to an increase in adipose tissue, inducing elevated circulating FFA levels, altering adipose tissue-derived factors such as increasing leptin (initially an appetite suppressant) and TNF $\alpha$ (known to induce peripheral insulin resistance), and decreasing adiponectin (sensitize insulin action) [17], followed by eventual visceral fat accumulation $[13,18]$. This will induce insulin resistance by altering glucose transport or inhibiting insulin-mediated glucose uptake pathways in cardiac muscle and possibly skeletal muscle, liver, and adipose tissues. It will further indirectly increase endogenous glucose production by inhibiting the insulin-mediated suppression of hepatic glycogenesis $[19,20]$, and increase FFA-induced insulin secretion exacerbated by FFA-induced insulin resistance [21].

Whether aspalathin has the ability to stimulate glucose uptake in isolated cardiomyocytes was first tested by establishing an aspalathin dose response in cardiomyocytes of young control rats ( $\vee$ Fig. 2A). This showed a significant reduction in glucose uptake for all three aspalathin dosages of $1 \mu \mathrm{M}$ aspalathin $(24 \pm 7 \% ; n=2$; $\mathrm{p}<0.001), 10 \mu \mathrm{M}$ aspalathin $(11 \pm 10 \% ; \mathrm{n}=3 ; \mathrm{p}<0.01)$, and $100 \mu \mathrm{M}$ aspalathin $(27 \pm 8 \% ; \mathrm{n}=3 ; \mathrm{p}<0.001)$ compared to basal $(100 \pm 4 \% ; n=9)$. DMSO $0.1 \%$, the effective vehicle concentration

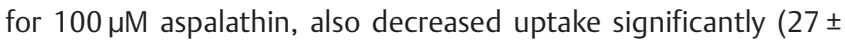
$8 \% ; n=9 ; p<0.001$ ) compared to basal. Trypan blue exclusion assays of isolated cardiomyocytes showed no significant differences in cell viability following separate isolations $(68 \pm 6 \% ; n=3)$ (Table 35 , Supporting Information). Similarly, PI staining of cardiomyo- 

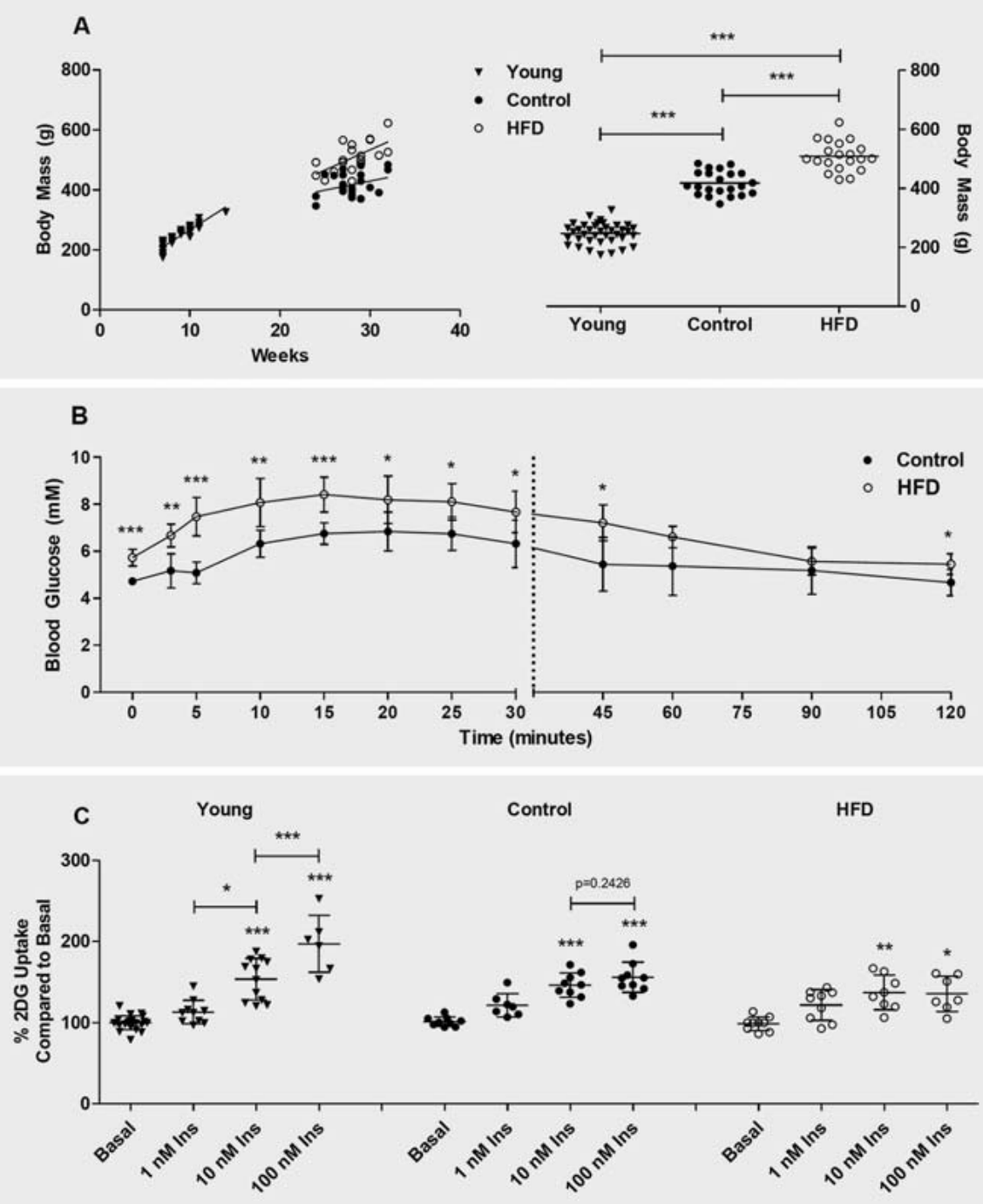

- Fig. 1 Effects of an HFD compared to young and age-matched control diets. A Body weight of rat models at time of sacrifice: young (7-14 weeks; $n=38$ ), control (24-32 weeks; $n=22$ ), and HFD (24-32 weeks; $n=20) .{ }^{* * *} P<0.001$ compared to other animal models. B Sucrose oral test of rats on a 16-week control diet or HFD. Rats were fasted overnight and blood glucose was measured for $0-120 \mathrm{~min}$ after $1 \mathrm{mg} / \mathrm{kg}$ body weight sucrose administration $(n=5-9) .{ }^{*} P<0.05,{ }^{* *} p<0.01,{ }^{* * *} p<0.001$ compared to the control. $C$ \%2DG uptake after a 45-min insulin dose response in isolated cardiomyocytes (young, control, and HFD; $\mathrm{n}=3-7$ ). ${ }^{* *} \mathrm{P}<0.01,{ }^{* * *} \mathrm{p}<0.001$ compared to the corresponding basal uptake using oneway ANOVA.

cytes from young rats ( $\mathrm{n}=1$, performed in triplicate) after 1 or $3 \mathrm{~h}$ of treatment with DMSO, aspalathin, or insulin also showed no significant difference in cell viability between the treatment groups (Table 3S, Supporting Information). Therefore, the observed suppression in glucose uptake was not due to DMSO toxicity.

Within the heart, glucose enters cells through either facilitated diffusion or active diffusion mediated by the glucose transporters GLUT1 and GLUT4. Glucose is always higher within the blood, than intracellularly, causing a glucose gradient that drives the influx of glucose. The gradient is maintained by abundant hexokinase enzymes, which phosphorylate glucose as it enters the cardiomyocytes, leaving the transport into cells as the rate-limiting step
[22]. In a study by Berenguer et al. [23] on 3T3-L1 adipocytes and L6 myotubes, they found that low concentrations of DMSO were able to induce GLUT1 and GLUT4 recruitment to the cell surface and simultaneously inhibit the activity of the glucose transporters. The half-life for reversing these effects were $t_{1 / 2} \sim$ 12 min in 3T3-L1 adipocytes, and could possibly be longer in cardiomyocytes. We also propose that since $0.1 \%$ DMSO was not toxic to the cells, the reduction in glucose uptake observed could be due to DMSO inhibiting GLUT4 activity - an effect exacerbated by an increasing DMSO concentration.

The possibility that aspalathin might indirectly effect glucose uptake in cardiomyocytes through co-mediating insulin's action in young control rats ( $\bullet$ Fig. $\mathbf{2 B - C}$ ) was explored. Co-treating 


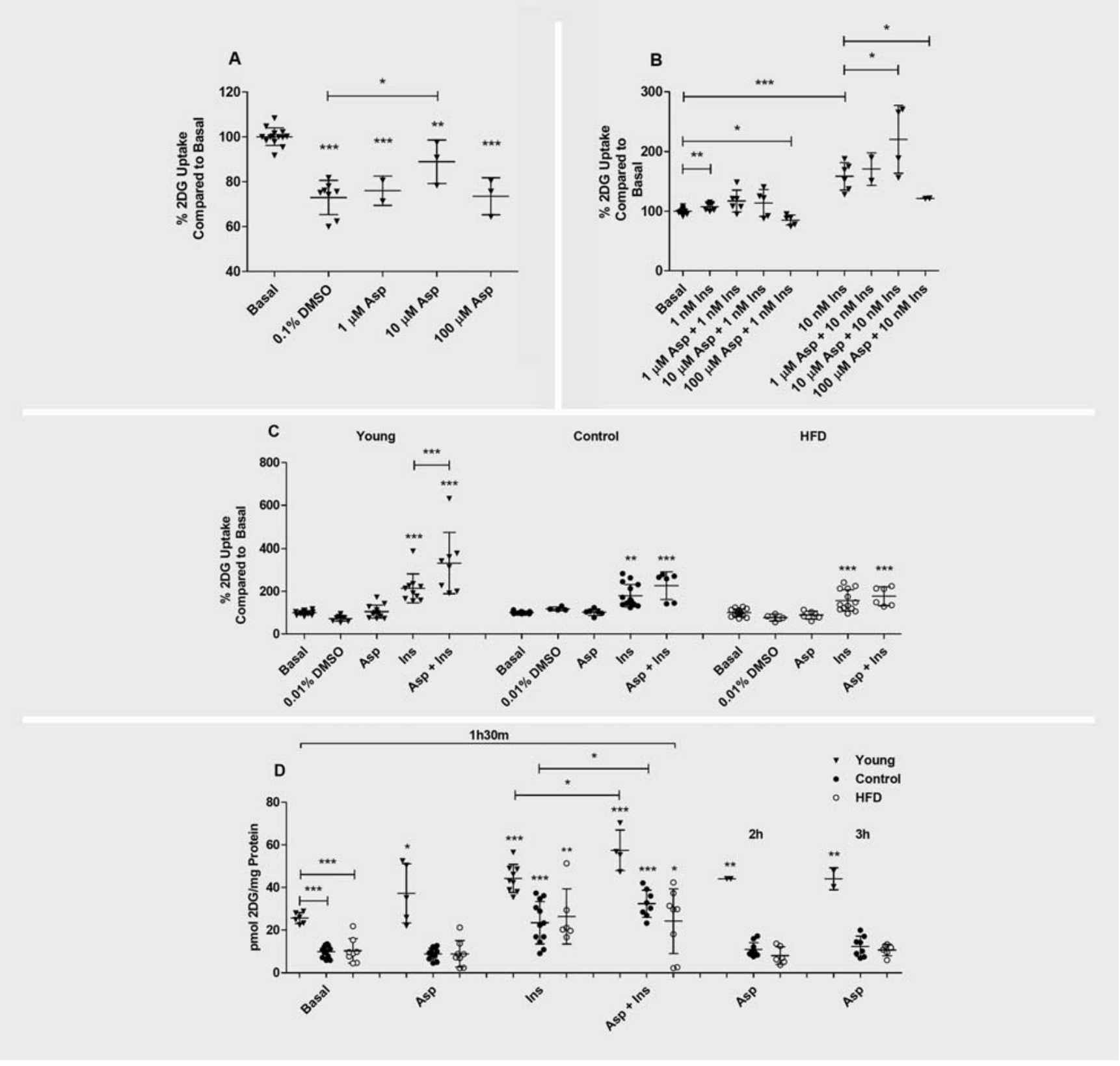

- Fig. 2 Glucose uptake in isolated cardiomyocytes from young, aged control, and HFD rats in response to aspalathin and insulin treatment. A \%2DG after $45 \mathrm{~min}$ of aspalathin dose response in isolated cardiomyocytes (young rats; $n=2-9$ ); ${ }^{*} p<0.05$ compared to $0.1 \%$ DMSO vehicle; ${ }^{* *} \mathrm{p}<0.01,{ }^{* * *} \mathrm{p}<0.001$ compared to basal uptake. B \%2DG after $45 \mathrm{~min}$ aspalathin and insulin dose response in cardiomyocytes (young rats; $\mathrm{n}=3) .{ }^{*} \mathrm{P}<0.05,{ }^{* *} \mathrm{p}<0.01,{ }^{* * *} \mathrm{p}<0.001$ compared to $10 \mathrm{nM}$ insulin, unless otherwise indicated. $\mathrm{C} \% 2 \mathrm{DG}$ uptake after 45 min aspalathin and insulin treatment in isolated cardiomyocytes (young, aged control, and HFD rats; $\mathrm{n}=3-5$ ). ${ }^{* *} \mathrm{P}<0.01,{ }^{* * *} \mathrm{p}<0.001$ compared to the corresponding basal uptake. $\mathrm{D}$ Absolute 2DG uptake after $1-3 \mathrm{~h}$ of treatment in isolated cardiomyocytes from rat models (young, control, and HFD rats; $\mathrm{n}=3-$ 6). Ins: $10 \mathrm{nM}$ insulin, Asp: $10 \mu \mathrm{M}$ aspalathin. ${ }^{*} \mathrm{P}<0.05,{ }^{* *} \mathrm{p}<0.01,{ }^{* * *} \mathrm{p}<0.001$ compared to the corresponding basal uptake, unless otherwise indicated.

$10 \mathrm{nM}$ insulin with increasing concentrations of aspalathin for 45 min showed an effective increase in glucose uptake of $62 \%$ for concentrations of $10 \mu \mathrm{M}$ aspalathin $(221 \pm 57 \%)$ compared to $10 \mathrm{nM}$ insulin $(158 \pm 23 \%$; $\mathrm{p}<0.001)$ ( $>$ Fig. 2 B), while the effect was dissipated when co-treating with $100 \mu \mathrm{M}$ aspalathin (121 $\pm 1 \%$ ). This infers that insulin plays an important role in eliciting aspalathin's response through increasing coactivation or co- expression of the insulin-dependent signaling pathway proteins. This mechanism has been noted before in palmitate-induced insulin resistant $\mathrm{C} 2 \mathrm{C} 12$ muscle cells that presented with a low glucose uptake response to treatment with insulin, but once co-treated with green rooibos extract (which has a high aspalathin content) there was a notable increase in glucose uptake [8]. However, in the present study, cardiomyocytes isolated from obese, insulin- 


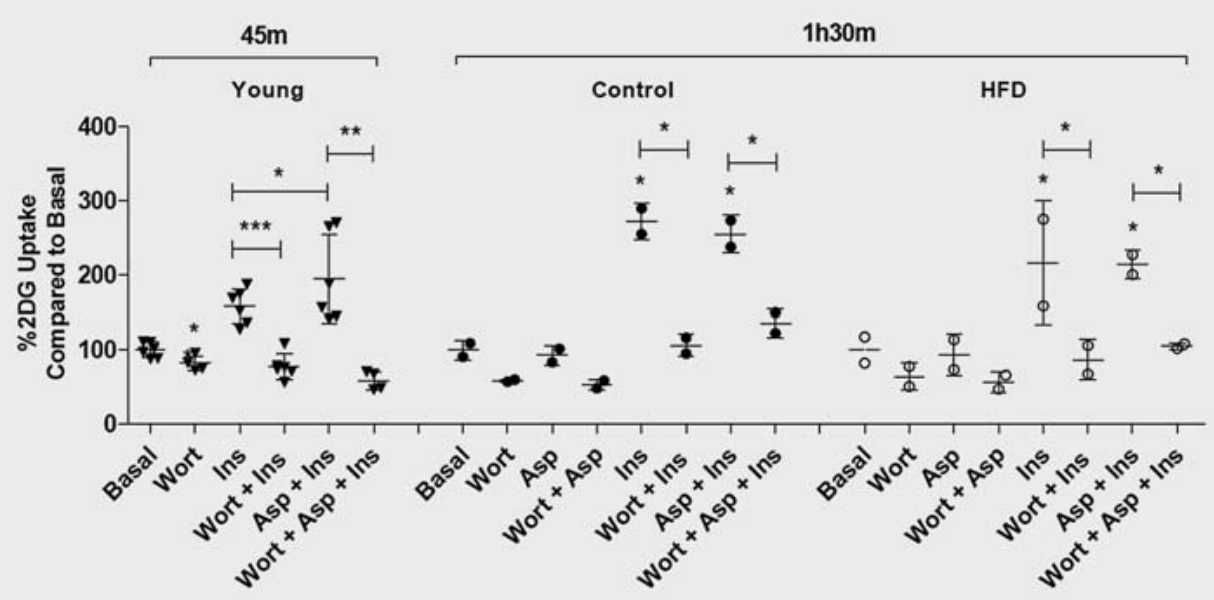

- Fig. 3 Glucose uptake after PI3K inhibition in isolated cardiomyocytes from young, aged control, and HFD rats. \%2DG uptake after wortmannin pretreatment followed by 45 min stimulation with aspalathin and insulin in cardiomyocytes from young rats $(n=3)$, and 90 min stimulation in aged control and HFD rats ( $n=2$ ). Wort: $100 \mathrm{nM}$ wortmannin, Asp: $10 \mu \mathrm{M}$ aspalathin, Ins: $10 \mathrm{nM}$ insulin. ${ }^{*} \mathrm{P}<0.05$ compared to the corresponding basal uptake, unless otherwise indicated.

resistant, and age-matched control rats showed no significant differences in acute glucose uptake when treated with aspalathin, or aspalathin in conjunction with insulin ( $\bullet$ Fig. $2 \mathbf{C}$ ). The fact that aspalathin in conjunction with insulin was able to acutely increase glucose uptake in cardiomyocytes from young control rats, but not in mature rats, indicates that the mechanisms of ageing, which independently reduce the sensitivity of the insulin signaling pathways [24], is an important factor diminishing aspalathin's glucose uptake potential.

The experiments were extended on ventricular cardiomyocytes to 3 h ( $\bullet$ Fig. 2D). Surprisingly, incubating cells with $10 \mu \mathrm{M}$ aspalathin for $1.5 \mathrm{~h}$ (a mere 45 min longer than in the acute model) resulted in a significant increase in glucose uptake in cardiomyocytes from young controls $(37.2 \pm 13.9 \mathrm{pmol} 2 \mathrm{DG} / \mathrm{mg}$ protein; $n=3 ; p<0.05)$, saturated at $2 \mathrm{~h}$ of treatment $(44.1 \pm$ $0.1 \mathrm{pmol} 2 \mathrm{DG} / \mathrm{mg}$ protein; $\mathrm{n}=2$; $\mathrm{p}<0.01$ ), with $3 \mathrm{~h}$ of treatment also having a similar result $(44.1 \pm 5.2 \mathrm{pmol} 2 \mathrm{DG} / \mathrm{mg}$ protein; $n=2 ; p<0.01$ vs. basal: $25.7 \pm 2.5 \mathrm{pmol} 2 \mathrm{DG} / \mathrm{mg}$ protein; $n=4$ ). The addition of aspalathin to insulin was able to significantly increase glucose uptake by $30 \%$ in the young group $(57.5 \pm$ $9.5 \mathrm{pmol} 2 \mathrm{DG} / \mathrm{mg}$ protein; $\mathrm{n}=3 ; \mathrm{p}<0.05)$ and by $38 \%$ in the aged control group $(32.4 \pm 6.4 \mathrm{pmol} 2 \mathrm{DG} / \mathrm{mg}$ protein; $\mathrm{n}=5 ; \mathrm{p}<0.05)$ compared to insulin alone $(44.3 \pm 6.5 \mathrm{pmol} 2 \mathrm{DG} / \mathrm{mg}$ protein and $23.5 \pm 10.0 \mathrm{pmol} 2 \mathrm{DG} / \mathrm{mg}$ protein, respectively). The HFD group showed no significant increases when treated with aspalathin and insulin (24.2 $\pm 15.1 \mathrm{pmol} 2 \mathrm{DG} / \mathrm{mg}$ protein; $\mathrm{n}=4 ; \mathrm{p}<0.05)$ or without insulin, but remained responsive to insulin treatment after $1.5 \mathrm{~h}(26.4 \pm 12.9 \mathrm{pmol} 2 \mathrm{DG} / \mathrm{mg}$ protein; $\mathrm{n}=3 ; \mathrm{p}<0.01)$ compared to basal $(10.3 \pm 5.7 \mathrm{pmol} 2 \mathrm{DG} / \mathrm{mg}$ protein; $n=4)$. No further increase in glucose uptake by aspalathin was observed for either older controls or HFD rats when the incubation time was extended to $3 \mathrm{~h}$. Consistently, younger rats had the most robust basal glucose uptake response $(25.7 \pm 2.5 \mathrm{pmol} 2 \mathrm{DG} / \mathrm{mg}$ protein; $n=4$ ), whereas aged rats had similar responses to each other
$(10.0 \pm 2.8 \mathrm{pmol} 2 \mathrm{DG} / \mathrm{mg}$ protein for control; $\mathrm{n}=6$ and $10.3 \pm 5.8 \mathrm{pmol} 2 \mathrm{DG} / \mathrm{mg}$ protein for HFD; $n=4 ; p<0.001$ ) ( $\vee$ Fig. 2D). The lack of effects of aspalathin stimulation in older, obese, insulin-resistant rats strengthens the argument that aspalathin's actions are in part dependent on the insulin signaling pathway. This was investigated using wortmannin, a PI3K inhibitor. Insulin stimulation results in glucose uptake through activation of PI3K, Akt, and translocation of GLUT4 to the plasma membrane [25]. Therefore, inhibiting PI3K through pretreatment with wortmannin should result in the inhibition of insulin's glucose uptake potential [26]. This was the case when wortmannin was administered before insulin and aspalathin treatment, which resulted in a loss of glucose uptake potential in cardiomyocytes from young rats ( $\bullet$ Fig. 3 ). Wortmannin at $100 \mathrm{nM}$ significantly decreased basal glucose uptake ( $82 \pm 10 \%$ vs. $100 \pm 10 \%, n=3$; $p<0.05)$. The remaining glucose uptake is the result of repetitive cardiomyocyte contraction [25]. Co-treating $10 \mathrm{nM}$ insulin with $100 \mathrm{nM}$ wortmannin significantly decreased glucose uptake (78 $\pm 17 \% ; n=3 ; p<0.001)$ compared to $10 \mathrm{nM}$ insulin alone $(158 \pm 23 \% ; n=3) \quad(\vee$ Fig. 3$)$. Furthermore, the addition of $100 \mathrm{nM}$ wortmannin completely inhibited all of the glucose uptake potential of the combination of aspalathin and insulin $(59 \pm 13 \% ; n=2 ; p<0.01)$. Likewise in older, obese, insulin-resistant rats and age-matched controls ( $\bullet$ Fig. $\mathbf{3}$ ).

Wortmannin $100 \mathrm{nM}$ was able to significantly decrease basal glucose uptake in control rats $(59 \pm 2 \%$ vs. $100 \pm 13 \% ; n=2$; $\mathrm{p}<0.05$ ) after $90 \mathrm{~min}$ of stimulation ( $\vee$ Fig. 3). Co-treating $10 \mathrm{nM}$ insulin with $100 \mathrm{nM}$ wortmannin significantly decreased glucose uptake in both control ( $106 \pm 15 \%$ vs. $272 \pm 25 \%$; $n=2$; $p<0.05$ ) and HFD rats $(87 \pm 28 \%$ vs. $217 \pm 83 \%$; $=2$; $p<0.05)$. Furthermore, inhibiting $\mathrm{PI} 3 \mathrm{~K}$ with $100 \mathrm{nM}$ wortmannin completely inhibited the additive effects of $10 \mathrm{nM}$ insulin and $10 \mathrm{uM}$ aspalathin on glucose uptake by cardiomyocytes from aged control rats (136 \pm 19 vs. $256 \pm 26 ; n=2 ; p<0.05)$. In a study performed on 
L6 myotubes, treatment with $2 \mathrm{mM}$ metformin (a known hypoglycemic agent and antidiabetic treatment) for $5 \mathrm{~h}$ in culture induced glucose uptake independent of insulin, but co-treatment with insulin resulted in a further activation of glucose uptake [27]. Similar to the action of metformin, we propose aspalathin is able to induce glucose uptake independent of insulin, but downregulation of the PI3K signaling pathway in older animals, and even more so in insulin-resistant animals, results in a desensitization of the entire insulin signaling pathway and subsequently suppress glucose uptake induced by aspalathin. This is the first time aspalathin's acute antidiabetic potential has been tested in isolated cardiomyocytes, whereas previous studies made use of cultured rat RIN-5F pancreatic cells, rat L6 myotubes, mouse C2C12 skeletal muscle cells, or human hepatoma CCL-13 cells eliciting a glucose

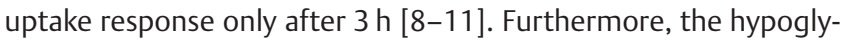
cemic effects observed after 5 weeks of dietary aspalathin administration in both $o b / o b$ and $d b / d b$ mice models possibly means that in order to elicit a significant response, aspalathin (and its metabolites) needs to accumulate over time.

This study demonstrated the effects on glucose uptake of relatively short-term in vitro treatment with aspalathin on cardiomyocytes isolated from the hearts of healthy, young, and aged rats, as well as aged obese and insulin-resistant rats. Aspalathin, as a pleiotropic compound, has a very specific dosage duration and elicits its effects in a dose-dependent manner. It induces myocardial glucose uptake directly and potentiated the effects of insulin in cardiomyocytes isolated from young rats, while in older animals, aspalathin had a more indirect effect on glucose uptake through enhancing insulin's action. Aspalathin also had no significant effect when used as a stimulant in heart cells from obese, insulin-resistant rats, indicative that aspalathin requires PI3K signaling pathway sensitivity to be beneficial (Fig. 1S, Supporting Information).

\section{Materials and Methods}

\section{Chemicals}

Synthetic aspalathin (purity of $\geq 98 \%$ as determined by HPLC and LC-MS) was supplied by the South African Medical Research Council. Euthanaze was supplied by Bayer Healthcare Animal Health. Blood glucose meter and strips were obtained from GlucoPlus. Millipore Rat/Mouse Insulin ELISA was purchased from Merck. BSA fraction $V$ (fatty acid free) and BSA fraction $V$ were purchased from Roche. 2DG and Emulsifier Scintillator Plus were purchased from Perkin-Elmer. Wortmannin (purity of $\geq 98 \%$ as determined by HPLC and LC-MS), propidium iodide, phloretin, and insulin were purchased from Sigma-Aldrich. Collagenase type 2 was purchased from Worthington Biochemical. GraphPad Prism 5 was obtained from Graphpad Software. All other consumables as well as reagents were purchased from Sigma-Aldrich and Merck.

\section{Ethics}

The experimental procedure was approved by the Committee for Ethical Animal Research of the University of Stellenbosch (Ethical Clearance: SU-ACUM14-00013. Obtained September 9, 2014). The revised South African National Standard for the care and use of laboratory animals for scientific purpose was followed (SABS, SANS 10386, 2008).

\section{Animal care}

Rats were housed in cages in a stable environment of $22^{\circ} \mathrm{C}, 40 \%$ humidity, and a 12-h artificial day/night cycle. Male Wistar rats ( 6 weeks old, $190 \pm 10 \mathrm{~g}$ ) were randomly selected and grouped into control and HFD groups. Control rats received commercial rat chow $(1272 \mathrm{~kJ} / 100 \mathrm{~g})$ and unlimited drinking water, whereas the HFD groups received a diet consisting of normal chow, supplemented with sucrose, condensed milk, and holsum fat (1354 kJ/ $100 \mathrm{~g}$ ) (Table 1S, Supporting Information). Additionally, young control rats (180-300 g) consuming commercial rat chow were used throughout the study as positive controls to verify the validity of experimental protocols.

\section{Sucrose administration test}

A sucrose administration test was used to determine the efficacy of the rats to clear blood glucose following oral ingestion of a $50 \%$ sucrose solution. Animals were fasted overnight (with access to drinking water) before being anesthetized by an intraperitoneal injection with a very low dose of sodium pentobarbital $(15 \mathrm{mg} /$ kg body weight). Initial fasting blood glucose levels were established from a tail prick using a glucometer. In addition, $1 \mathrm{~mL}$ of fasting blood collected directly from the carotid artery was used in subsequent insulin assays. Thereafter, a solution of $50 \%$ sucrose at a dose of $1 \mathrm{mg} / \mathrm{kg}$ body weight was administered by oral gavage, and blood glucose levels were monitored between 0 and 120 min. Afterwards, the animals were allowed to recover for one week from this metabolic insult before being sacrificed in other experiments.

\section{Insulin assay}

Serum from the fasting blood was used to determine insulin levels of the animals using a Millipore Rat/Mouse Insulin ELISA kit according to the manufacturer's instructions. The HOMA-IR index was calculated using HOMA2 Calculator 2.2.3 software.

\section{Non-fasting blood glucose}

Blood glucose concentrations of the anesthetized rats were determined from a drop of blood collected from a tail prick using a hand-held glucometer.

\section{Visceral fat}

The visceral fat of the control and HFD animals were dissected and weighed.

\section{Isolation of cardiomyocytes}

Buffer compositions are shown in Table 4S, Supporting Information. Rats were anesthetized with sodium pentobarbital $(160 \mathrm{mg} /$ $\mathrm{kg}$ ) (Euthanaze). Hearts were quickly excised (<1 min after first incision) and arrested in ice-cold Krebs-Henseleit buffer. Cardiomyocytes in an unstimulated state were isolated essentially as described previously [28]. The hearts were mounted via the aorta onto a Langendorff perfusion system ( $<2$ min after removal) and retrogradely perfused with HEPES buffer (Buffer A) at $37^{\circ} \mathrm{C}$, gassed with $100 \% \mathrm{O}_{2}$ for 5 min to rinse out the residual blood. 
The perfusion medium was then switched to a recirculating medium containing $0.1 \%$ type 2 collagenase and $15 \mathrm{mM}$ 2,3-BDM (Buffer B). After $20 \mathrm{~min}$, the calcium concentration was gradually increased to $200 \mu \mathrm{M}$. Perfusion was continued until the perfusate streamed continuously from the heart or 40 min maximum. After digestion, the hearts were removed and the ventricles were carefully isolated from the atrial and vascular remnants, minced with tweezers, and suspended in Buffer C containing $200 \mu \mathrm{M}$ $\mathrm{CaCl}_{2}$ and half the concentration of collagenase and 2,3-BDM. The suspension was placed in a flat-bottomed flask in a shaking incubator at $110 \mathrm{rpm}$ (circular orbit of $19 \mathrm{~mm}$ ) and $37^{\circ} \mathrm{C}$, and further digested for $20 \mathrm{~min}$ in the presence of $100 \% \mathrm{O}_{2}$ with the calcium concentration gradually raised to $1.25 \mathrm{mM}$ over the last 5min period. The isolated cells were filtered (nylon mesh: $200 \times 200 \mu \mathrm{m}$ ) and gently spun down at $10 \times g$ for $3 \mathrm{~min}$. The pellet obtained was resuspended in a fatty acid free BSA-rich buffer (Buffer D) and the viable cells were allowed to settle through the solution for $5 \mathrm{~min}$. The supernatant was aspirated, and the pellet resuspended in Buffer D and slowly rotated (30 rpm with a 19-mm circular orbit) at $37^{\circ} \mathrm{C}$ for at least $1 \mathrm{~h}$. After recovery, the cell's viability was routinely $65-70 \%$, as determined by trypan blue exclusion (Table 3S, Supporting Information). Each heart typically yielded approximately 5 million cardiomyocytes. The cells were washed three times in a substrate-free medium (Buffer E) and allocated for experimentation.

\section{Propidium iodide staining}

Myocardial cell viability in response to treatment was determined by 1 or $3 \mathrm{~h}$ pretreatment with either $0.01 \%$ DMSO (vehicle), $10 \mu \mathrm{M}$ aspalathin, or $10 \mathrm{nM}$ insulin, and stained using $5 \mu \mathrm{M}$ PI. Treatments were performed in duplicate with one series stained (PI) and the other unstained (negative). Both series were incubated for $15 \mathrm{~min}$ at room temperature in the dark. The samples were then analyzsed at simultaneous $617 \mathrm{~nm} / 535 \mathrm{~nm}$ wavelengths using FACS analysis. Complete FACS analysis is described in the Supporting Information section.

\section{Glucose uptake assay}

2DG uptake by adult ventricular myocytes was essentially determined as published previously [26]. This method renders cells that are calcium tolerant but are in a quiescent and unstimulated state. For the glucose uptake assay, the isolated cardiomyocytes were incubated for a total of $1-3 \mathrm{~h}$ at $37^{\circ} \mathrm{C}$ in an oxygenated, substrate-free medium (Buffer $\mathrm{E}$ ), with treatments commencing at the 5-min time point. Aspalathin, wortmannin and phloretin were dissolved in DMSO as stock solutions of $1 \mathrm{mM}, 2 \mathrm{mM}$ and $64 \mathrm{mM}$, respectively, and stored as aliquots at $-80^{\circ} \mathrm{C}$. Insulin stock solution was similarly made up as a $10 \mu \mathrm{M}$ solution in Buffer $\mathrm{E}$ and stored as aliquots at $-80^{\circ} \mathrm{C}$. All four treatments were diluted with Buffer $\mathrm{E}$ to their respective concentrations. At 35-150 min after stimulation of the cells, glucose uptake was initiated by the addition of $1.8 \mu \mathrm{M}$ (specific activity, $1.5 \mu \mathrm{Ci} / \mathrm{mL}$ ) 2DG. The experiment was allowed to proceed for $30 \mathrm{~min}$, after which the glucose uptake reaction was stopped by adding a final concentration of $400 \mu \mathrm{M}$ phloretin. Cell suspensions were microfuged at $14000 \times$ $g$ for $90 \mathrm{sec}$ at room temperature. The resultant supernatant was aspirated and the cells were washed with HEPES buffer to remove all traces of radiolabelled 2DG. Samples were dissolved in $1 \mathrm{~N}$ $\mathrm{NaOH}$ and then diluted to a final concentration of $0.5 \mathrm{~N} \mathrm{NaOH}$. An aliquot was used to assay the protein content in duplicate by the method of Lowry et al. [29], while $100 \mu \mathrm{L}$ per sample in duplicate were counted for radioactivity. A sample containing only scintillation fluid was used as a blank, and 1.8 $\mu \mathrm{M}$ 2DG were used to measure the total radioactive count for specific activity determination.

\section{Statistical analysis}

Unless stated otherwise, all results are presented as the means \pm standard deviation. For comparative studies, statistical analysis was performed with a Student's t-test (unpaired) or one-way analysis of variance (ANOVA) followed by Bonferroni multiple comparisons post-test using GraphPad Prism 5. P $<0.05$ was considered significant.

\section{Supporting information}

HPLC analysis of the aspalathin used in this study has been published previously and the results thereof are available at http:// dx.doi.org/10.1016/j.chroma.2014.12.078 (Data is not available free of charge).

Dietary composition for the rat models, insulin resistance assessment criteria, cell viability assay results, and buffer compositions used during isolation protocols are available as Supporting Information.

\section{Acknowledgements}

The study was funded by the Harry Crossley Foundation, and the Biomedical Research and Innovation Platform of the South African Medical Research Council.

\section{Conflict of Interest}

The authors declare no conflict of interest.

\section{References}

[1] World Health Organization. Cardiovascular Diseases. Global Initiative. World Health Organization. Available at http://www.who.int/ cardiovascular_diseases/en/. Accessed February 5, 2017

[2] Defronzo RA. Pathogenesis of type 2 diabetes mellitus. Med Clin North Am 2004; 88: 787-835

[3] Misbin Rl. Evaluating the safety of diabetes drugs: perspective of a food and drug administration insider. Diabetes Care 2005; 28: 2573-2576

[4] Abdulreda MH, Rodriguez-Diaz R, Caicedo A, Berggren PO. Liraglutide compromises pancreatic $\beta$ cell function in a humanized mouse model. Cell Metab 2016; 23: 541-546

[5] Boussageon R, Bejan-Angoulvant T, Saadatian-Elahi M, Lafont S, Bergeonneau C, Kassai B, Erpeldinger S, Wright JM, Gueyffier F, Cornu C. Effect of intensive glucose lowering treatment on all cause mortality, cardiovascular death, and microvascular events in type 2 diabetes: meta-analysis of randomised controlled trials. BMJ 2011; 343: d4169

[6] Van der Merwe JD, Joubert E, Richards ES, Manley M, Snijman PW, Marnewick JL, Gelderblom WCA. A comparative study on the antimutagenic properties of aqueous extracts of Aspalathus linearis (rooibos), different Cyclopia spp. (honeybush) and Camellia sinensis teas. Mutat Res 2006; 611: 42-53 
[7] Marnewick JL, Rautenbach F, Venter I, Neethling H, Blackhurst DM, Wolmarans P, Macharia M. Effects of rooibos (Aspalathus linearis) on oxidative stress and biochemical parameters in adults at risk for cardiovascular disease. J Ethnopharmacol 2011; 133: 46-52

[8] Mazibuko SE, Muller CJF, Joubert E, De Beer D, Johnson R, Opoku AR, Louw J. Amelioration of palmitate-induced insulin resistance in $\mathrm{C} 2 \mathrm{C} 12$ muscle cells by rooibos (aspalathus linearis). Phytomedicine 2013; 20 : 813-819

[9] Kawano A, Nakamura H, Hata S, Minakawa M, Miura Y, Yagasaki K. Hypoglycemic effect of aspalathin, a rooibos tea component from Aspalathus linearis, in type 2 diabetic model db/db mice. Phytomedicine 2009; 16 : 437-443

[10] Muller CJF, Joubert E, de Beer D, Sanderson M, Malherbe C], Fey S], Louw J. Acute assessment of an aspalathin-enriched green rooibos (Aspalathus linearis) extract with hypoglycemic potential. Phytomedicine 2012; 20: 32-39

[11] Son M], Minakawa M, Miura Y, Yagasaki K. Aspalathin improves hyperglycemia and glucose intolerance in obese diabetic ob/ob mice. Eur J Nutr 2013; 52: 1607-1619

[12] Huisamen B, George C, Dietrich D, Genade S. Cardioprotective and antihypertensive effects of Prosopis glandulosa in rat models of pre-diabetes: cardiovascular topics. Cardiovasc J Afr 2013; 24: 10-16

[13] Blüher M. Adipose tissue dysfunction contributes to obesity related metabolic diseases. Best Pract Res Clin Endocrinol Metab 2013; 27: 163-177

[14] Grundy SM. Pre-diabetes, metabolic syndrome, and cardiovascular risk. I Am Coll Cardiol 2012; 59: 635-643

[15] Norris JM, Rich SS. Genetics of glucose homeostasis: implications for insulin resistance and metabolic syndrome. Arterioscler Thromb Vasc Biol 2012; 32: 2091-2096

[16] Huisamen B, Genis A, Marais E, Lochner A. Pre-treatment with a DPP-4 inhibitor is infarct sparing in hearts from obese, pre-diabetic rats. Cardiovasc Drugs Ther 2011; 25: 13-20

[17] Yadav A, Kataria MA, Saini V, Yadav A. Role of leptin and adiponectin in insulin resistance. Clin Chim Acta 2013; 417: 80-84
[18] Ding L, Song A, Dai M, Xu M, Sun W, Xu B, Sun J, Wang T, Xu Y, Lu J, Wang $\mathrm{W}, \mathrm{Bi} Y$, Ning $\mathrm{G}$. Serum lipoprotein (a) concentrations are inversely associated with T2D, prediabetes, and insulin resistance in a middle-aged and elderly Chinese population. J Lipid Res 2015; 56: 920-926

[19] Boden G, Shulman GI. Free fatty acids in obesity and type 2 diabetes: defining their role in the development of insulin resistance and beta-cell dysfunction. Eur J Clin Invest 2002; 32: 14-23

[20] Boden G. Obesity, insulin resistance and free fatty acids. Curr Opin Endocrinol Diabetes Obes 2011; 18: 139-143

[21] Boden G. Free fatty acids, insulin resistance, and type 2 diabetes mellitus. Proc Assoc Am Physicians 1999; 111: 241-248

[22] Montessuit C, Lerch R. Regulation and dysregulation of glucose transport in cardiomyocytes. Biochim Biophys Acta 2013; 1833: 848-856

[23] Berenguer M, Zhang J, Bruce MC, Martinez L, Gonzalez T, Gurtovenko AA, Xu T, Le Marchand-Brustel Y, Govers R. Dimethyl sulfoxide enhances GLUT4 translocation through a reduction in GLUT4 endocytosis in insulin-stimulated 3T3-L1 adipocytes. Biochimie 2011; 93: 697-709

[24] Frøsig C, Jensen TE, Jeppesen J, Pehmøller C, Treebak JT, Maarbjerg S], Kristensen JM, Sylow L, Alsted TJ, Schjerling P, Kiens B, Wojtaszewski JF. AMPK and insulin action - responses to ageing and high fat diet. PLoS One 2013; 8: e62338

[25] Fu Z, Gilbert ER, Liu D. Regulation of insulin synthesis and secretion and pancreatic beta-cell dysfunction in diabetes. Curr Diabetes Rev 2013; 9: 25-53

[26] Yeh JI, Gulve EA, Rameh L, Birnbaum M]. The effects of wortmannin on rat skeletal muscle. Dissociation of signaling pathways for insulin- and contraction-activated hexose transport. J Biol Chem 1995; 270: 21072111

[27] Purintrapiban J, Ratanachaiyavong S. The effects of insulin and metformin on glucose uptake in L8 myotubes. Sci Asia 2003; 29: 341-346

[28] Fischer $\mathrm{Y}$, Rose $\mathrm{H}$, Kammermeier H. Highly insulin-responsive isolated rat heart muscle cells yielded by a modified isolation method. Life Sci 1991; 49: 1679-1688

[29] Lowry HO, Rosebrough JN, Farr AL, Randall JR. Protein measurement with the folin phenol reagent. J Biol Chem 1951; 193: 265-275 